\title{
Influence of the Polymer Addition in Quenching Water on the Mechanical Properties of Aluminium Alloy Sheets
}

\author{
Gheorghe POPA \\ ALRO SA, Romania, gpopa@alro.ro \\ Maria STOICANESCU \\ Transilvania University of Brasov, Romania, stoican.m@unitbv.ro \\ Marin PETRE \\ ALRO SA, Romania, mapetre@alro.ro \\ Alexandra Valerica ACHIM \\ ALRO SA, Romania, anecola@alro.ro
}

\begin{abstract}
The main method to optimize the mechanical properties of the aluminium alloy sheets during quenching process is the control of the coolant agent. This optimization can be done by controlling the temperature and / or the composition of the coolant. In this work the influence of the composition of the coolant on the mechanical properties was studied by adding polymers. In order to establish the influence of the addition of polymer in the demineralized water on the mechanical properties of the aluminium alloy sheets, several tests were performed with different concentrations of the polymer in demineralized water. The experiments were performed on 6082 aluminium alloy sheets with a thickness of $5 \mathrm{~mm}$. The quenching process of the aluminium alloy sheets was performed by immersion in a stainless steel vessel with a capacity of 10 litres. The obtained results show that the addition of polymer in demineralized water does not negatively influence the mechanical properties: ultimate tensile strength, yield tensile strength and elongation at break.
\end{abstract}

\section{Keywords}

quenching, polymer, mechanical properties, aluminium alloy

\section{Introduction}

The typical heat treatment for quenchable aluminium alloys is to settle the solution treatment to about $500{ }^{\circ} \mathrm{C}$ (the temperature being very close to the melting point of each alloy) to ensure that all hardening compounds are dissolved in the solution. The material is then quenched in demineralized water or with various additives. After quenching the products are straightened, then artificially aged at a relatively low temperature (from $120^{\circ} \mathrm{C}$ to $180{ }^{\circ} \mathrm{C}$, depending on the alloy) so as to obtain the desired final properties and metallurgical state imposed in norms and specifications.

The objective of quenching is to preserve the super-saturated solid solution formed at the solution temperature, by rapid cooling to a lower temperature. If the quenching speed is too fast, then the properties are obtained, but excessive deformations or residual stresses can occur due to high thermal gradients [1]. In case of too slow quenching, there are precipitations of excessive hardening elements at the grain limit that no longer participate in increasing the properties of the material [2]. In order to reduce the distortions due to quenching [3], but without major influences on obtaining the mechanical characteristics, for aluminium alloys were developed more efficient solutions to partially or completely replace the demineralized water [4].

One of the solutions is to use the polymers in combination with demineralized water, which can provide a quenching rate between the water and oil [5]. The polymers are used for some time in the aerospace industry to control and minimize the deformation occurring the quenching of the aluminium alloy parts [6]. Unknown in the use of polymers remains the concentration that must be used, which depends on its composition and the requested properties [7].

In this paper the influence of addition of polymer for different concentration in the demineralized water on the mechanical properties of the 6082 aluminium alloy sheets was studied. 


\section{Experimental}

Considering the conditions limited by the dimensions of the furnace from the laboratory equipment, several samples were taken with the dimensions $200 \mathrm{~mm} \times 160 \mathrm{~mm}$, from a sheet with a thickness of $5 \mathrm{~mm}$, alloy 6082 .

After the solution at a temperature of $550{ }^{\circ} \mathrm{C}$ made in the furnace within the Chemical Laboratory, the actual quenching of the samples was performed by immersion in a stainless steel vessel with a capacity of 10 litres.

The demineralized water used in the experiments was provided by a Specialised Technological Component for Processing and Recirculation of Softened Water Required in the Research of Aluminium Alloy Plates Quenching Process (Figure 1).

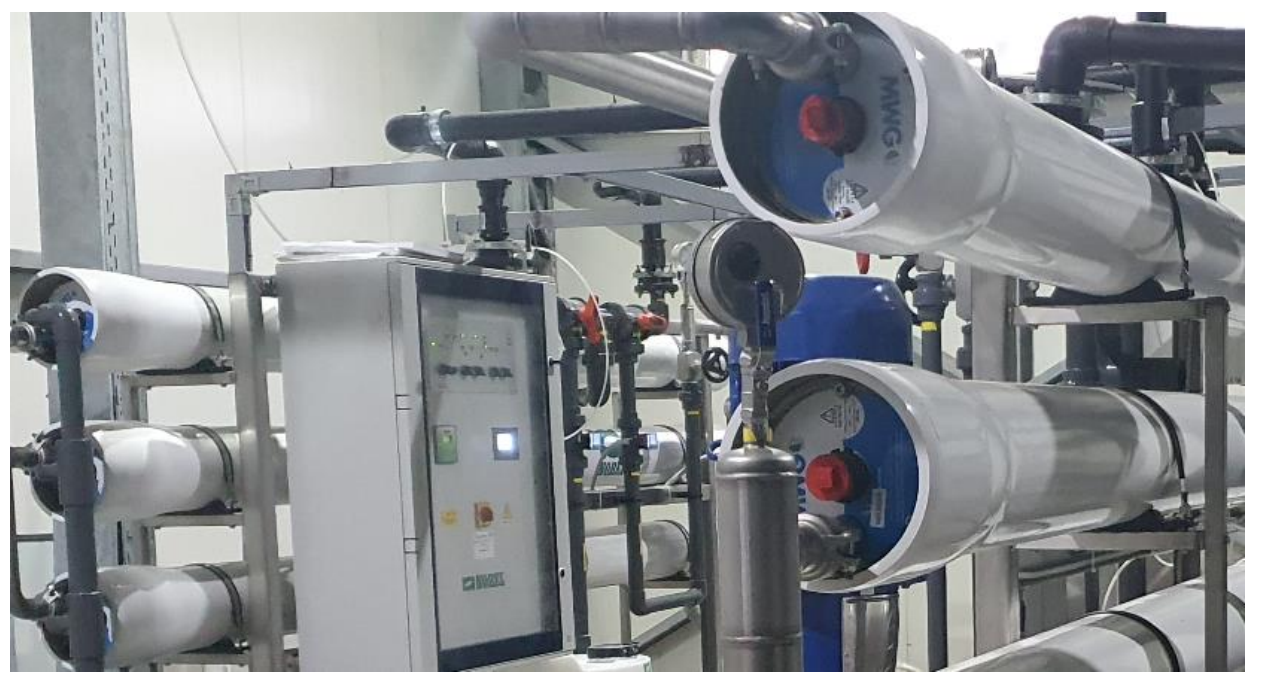

Fig. 1. Specialised Technological Component for Processing and Recirculation of Softened Water Required in the Research of Aluminium Alloy Plates Quenching Process

Table 1 details the preparation of polymers in water for each quenching test performed in the laboratory. The polymer used in these experiments was provided by Quaker Houghton Company [8].

Table 1. Concentrations of polymers used in the experiments performed

\begin{tabular}{cccccc|}
$\begin{array}{c}\text { Test } \\
\text { no. }\end{array}$ & $\begin{array}{c}\text { Demineralized } \\
\text { water } \\
{[\mathrm{ml}]}\end{array}$ & $\begin{array}{c}\text { Polymer } \\
\text { add } \\
{[\mathrm{ml}]}\end{array}$ & $\begin{array}{c}\text { Total } \\
\text { polymer in } \\
\text { solution } \\
{[\mathrm{ml}]}\end{array}$ & $\begin{array}{c}\text { TOTAL solution } \\
\text { (demineralized } \\
\text { water and polymer add) } \\
{[\mathrm{ml}]}\end{array}$ & $\begin{array}{c}\text { Polymer in } \\
\text { solution } \\
{[\%]}\end{array}$ \\
\hline $\mathbf{1}$ & 6000 & 0 & 0 & 0 & $\mathbf{0}$ \\
\hline $\mathbf{2}$ & 7125 & 0 & 375 & 7500 & $\mathbf{5}$ \\
\hline $\mathbf{3}$ & 6000 & 667 & 667 & 6667 & $\mathbf{1 0}$ \\
\hline $\mathbf{4}$ & 6000 & 392 & 1059 & 7059 & $\mathbf{1 5}$ \\
\hline $\mathbf{5}$ & 6000 & 441 & 1500 & 7500 & $\mathbf{2 0}$ \\
\hline $\mathbf{6}$ & 6000 & 500 & 2000 & 8000 & $\mathbf{2 5}$ \\
\hline
\end{tabular}

In order for the increase of the solution temperature not to influence the test results, the tests were performed on different days, so that the measured temperature of the quenching solution was $26^{\circ} \mathrm{C}$ at each test. It was also observed that after each quenching, the water temperature reached $32{ }^{\circ} \mathrm{C}$.

To make a comparison with the current situation, no polymers were used in the first experiment. In the next experiments the concentration of polymers was increased with $5 \%$ for each test, from 5 to $25 \%$.

An appreciable layer of additive remained on the samples, layer that required accentuated washing the sample with water for removal. 


\section{Results. Discussion}

In Table 2, the identification data of the samples and the values of the mechanical properties obtained for the 6 samples tested in different concentrations of polymers in the demineralized water were extracted from the Test Report issued by the ZWICK application of the traction machine.

Table 2. Mechanical properties after quenching for different values of the polymer concentration

\begin{tabular}{cccc}
\hline $\begin{array}{c}\text { Sample } \\
\text { no. }\end{array}$ & $\begin{array}{c}\mathbf{R m} \\
{[\mathrm{MPa}]}\end{array}$ & $\begin{array}{c}\mathbf{R p}_{\mathbf{0 . 2}} \\
{[\mathrm{MPa}]}\end{array}$ & $\begin{array}{c}\mathbf{A}_{\mathbf{5 0 m m}} \\
{[\%]}\end{array}$ \\
\hline 1 & 291 & 168 & 27.5 \\
2 & 293 & 159 & 29.5 \\
3 & 292 & 158 & 29.5 \\
4 & 297 & 161 & 31.0 \\
5 & 294 & 158 & 32.0 \\
6 & 281 & 150 & 29.0 \\
\hline
\end{tabular}

The evolution of the mechanical properties after quenching for different values of the polymer concentration is represented graphically in Figure 2.

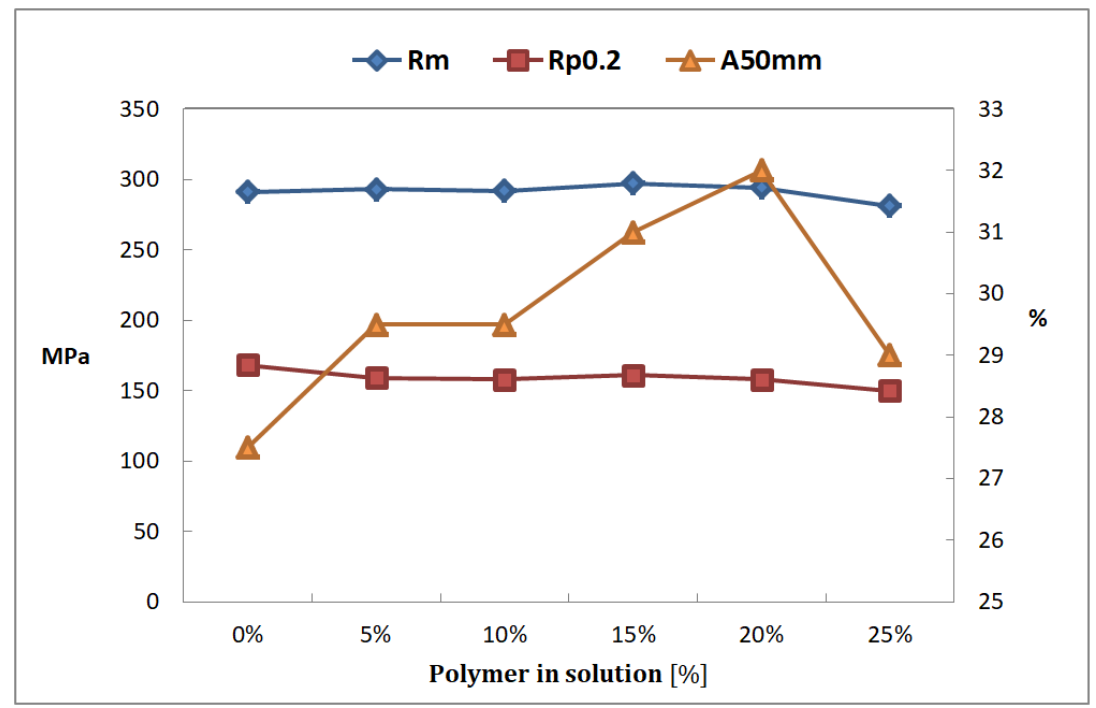

Fig. 2. Evolution of the mechanical properties after quenching for different values of the polymer concentration

From the analysis of the results obtained after quenching for the ultimate tensile strength $(\mathrm{Rm})$ and yield tensile strength $\left(R p_{0.2}\right)$ depending on the polymer concentration in the demineralized water in laboratory testing, a dependence between these characteristics cannot be established as the results obtained are similar. Instead, for elongation at break $\left(A_{50 \mathrm{~mm}}\right)$, a slightly increasing trend is observed with the addition of polymers in demineralized water and a decrease in elongation for a value of the polymer concentration of $25 \%$.

After the solution heat treatment and quenching, the 6 samples were subjected to the artificial ageing heat treatment in the lab.

In Table 3, the identification data of the samples and the values of the mechanical properties obtained after artificial ageing heat treatment for the 6 samples tested in different concentrations of polymers in the demineralized water are presented.

The evolution of the mechanical properties after artificial ageing heat treatment for different values of the polymer concentration is represented graphically in Figure 3. 
RECENT, Vol. 21, no. 3(62), 2020

Table 3. Mechanical properties after artificial ageing heat treatment for different values of the polymer concentration

\begin{tabular}{cccc}
\hline $\begin{array}{c}\text { Sample } \\
\text { no. }\end{array}$ & $\begin{array}{c}\text { Rm } \\
{[\mathrm{MPa}]}\end{array}$ & $\begin{array}{c}\mathbf{R p}_{\mathbf{0} .2} \\
{[\mathrm{MPa}]}\end{array}$ & $\begin{array}{c}\mathbf{A}_{\mathbf{5 0 m m}} \\
{[\%]}\end{array}$ \\
\hline 1 & 322 & 275 & 18.5 \\
2 & 340 & 295 & 17.0 \\
3 & 344 & 288 & 18.0 \\
4 & 339 & 279 & 18.0 \\
5 & 340 & 294 & 17.5 \\
6 & 336 & 290 & 17.5 \\
\hline
\end{tabular}

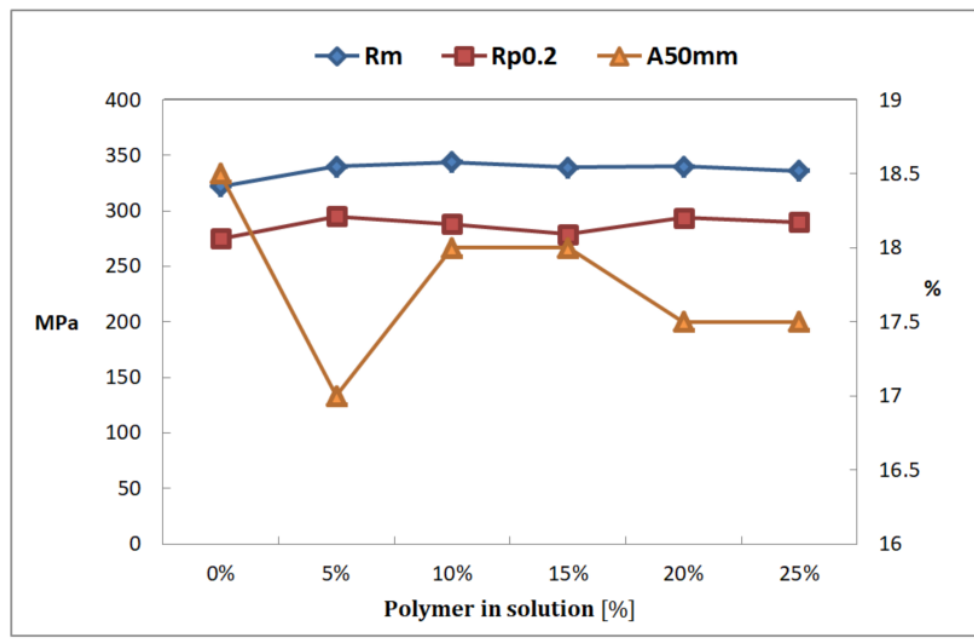

Fig. 3. Evolution of the mechanical properties after artificial ageing heat treatment for different values of the polymer concentration

From the analysis of the results obtained after artificial ageing heat treatment for ultimate tensile strength $(R m)$, yield tensile strength $\left(R p_{0.2}\right)$ and elongation at break $\left(A_{50 \mathrm{~mm}}\right)$, depending on the polymer concentration in the demineralized water, it is observed that the values for $R m, R p_{0.2}$ and $A_{50 m m}$ obtained for sample number 1 in which $100 \%$ demineralized water was used for quenching are comparable with the values of the characteristics in the other samples in which polymer was used in concentrations 5, 10, 15, 20 and $25 \%$.

\section{Conclusions}

This study was conducted to establish in the laboratory regime the influence of the addition of a polymer in demineralized water on mechanical properties of aluminium alloy sheets for improvement the quality of the quenchable aluminium alloy products.

From the analysis of the results of the laboratory test regarding the mechanical properties depending on the polymer concentration in demineralized water ( 0 to $25 \%, 5$ to 5 percent), it was not highlighted any negatively influence of the polymer addition on the mechanical properties.

Future work with more relevant conclusions is being finalized on the influence of the polymer addition in quenching water on the deformation and residual stresses of aluminium alloy sheets.

Future research will focus on developing a mathematical model of the immersion quenching process and to perform simulations based on different values for the polymers concentration.

\section{Acknowledgements}

Part of the cost of the industrial equipment used to obtain the results presented in this work was funded by European Union through Competitiveness Operational Programme, Priority Axis 1 
Research, Technological Development and Innovation, within the project "Investments in the R\&D Department of ALRO aiming at improving the research infrastructure for the aluminium alloy heat treated plates with high qualification industrial applications", based on the Funding Contract no. 42/05.09.2016.

The authors gratefully acknowledge of the Quaker Houghton company support in carrying out the experimental work embodied herein.

\section{References}

1. Totten G., Bates C., Clinton N. (Eds.) (1993): Handbook of Quenchants and Quenching Technology. ASM International, ISBN 9781615031726

2. Prime M.B., Hill M.R. (2002): Residual stress, stress relief, and inhomogeneity in aluminum plate. Scripta Materialia, ISSN 1359-6462, Vol. 46, Is. 1, pp. 77-82, https://doi.org/10.1016/S1359-6462(01)01201-5

3. Mackenzie D.S. (2003): Quenching and the Control of Residual Stresses and Distortion in Aluminum. Int. Conf. on Structural Aluminum Casting, Orlando, FL, USA, https://www.researchgate.net/publication/303565859

4. Totten G., Webster G.M., Bates C.E. (1998). An overview of aluminum quenching with polymer quenchants. Industrial Heating, ISSN 0019-8374, Nov. 1998, pp. 61-66, https://www.researchgate.net/publication/292900923

5. Canale L.C.F. Kavalco P.M., Totten G.E. (2011): Distortion Reduction by Aqueous Polymer Quenching of Aluminum Alloys. Industrial Heating, https://www.industrialheating.com/articles/89789-distortion-reduction-byaqueous-polymer-quenching-of-aluminum-alloys

6. Tiryakioglu M., Totten G.E. (1998): Quenching Aluminum Components in Water: Problems and Alternatives. Heat Treating, Proceedings of the 18th Conference (ASM International), ISBN 0-87170-626-1, pp. 156-165, https://www.asminternational.org/home/-/journal content/56/10192/CP1998HT156/CONFERENCE-PAPER

7. Totten G.E., Sun Y.H., Liščić B., Kobasko N.I. (1998): Polymer Quenching Technology: An Overview. $11^{\text {th }}$ Congress of the International Federation of Heat Treatment and Surface Engineering - 4th ASM Heat Treatment and Surface Engineering Conference in Europe Proceedings, ISBN 8885298311, pp. 141-150, https://www.tib.eu/en/search/id/BLCP\%3ACN031555546/Polymer-quenching-technology-an-overview/

8. Information on https://home.quakerhoughton.com/ 